\title{
A NOTE ON PRESERVERS OF PSEUDO SPECTRUM OF MATRIX PRODUCTS
}

\author{
Mohamed Bendaoud, Ayyoub Benyouness and Mustapha Sarih
}

Abstract. Let $\mathscr{M}_{2}$ be the algebra of $2 \times 2$ complex matrices. For $\varepsilon>0$, complete descriptions are given of the maps of $\mathscr{M}_{2}$ leaving invariant the $\varepsilon$-pseudo spectrum of $A * B$, where $A * B$ stands either for the Jordan semi-triple product $A B A$ or the skew product $A B^{*}$ on matrices.

Mathematics subject classification (2010): 47B49, 47A10, 47A25.

Keywords and phrases: Operator, pseudo spectrum, pseudo spectral radius, nonlinear preservers.

\section{REFERENCES}

[1] M. Bendaoud, Preservers of local spectrum of matrix Jordan triple products, Linear Algebra Appl., 471, 1, 2015, 604-614.

[2] M. Bendaoud, A. Benyouness And M. SARIH, Preservers of pseudo spectral radius of operator products, Linear Algebra Appl., 489, 15 January, 2016, 186-198.

[3] M. Bendaoud, A. Benyouness And M. SARIH, Preservers of pseudo spectra of operator Jordan triple products, Oper. Matrices, 10, 1, 2016, 45-56.

[4] M. BEndaoud, A. Benyouness AND M. SARIH Nonlinear maps preserving the pseudo spectral radius of skew semi-triple products of operators, Acta Sci. Math. (Szeged), 84, 1-2, 2018, 39-47.

[5] M. BENDAOUd, M. JABBAR AND M. SARIH, Preservers of local spectra of operator products, Linear Multilinear Algebra, 63, 4, 2015, 806-819.

[6] R. BhatiA, P. ŠEMrL AND A. R. Sourour, Maps on matrices that preserve the spectral radius distance, Studia Math., 134, 1-3, 1999, 99-110.

[7] J. T. CHAN, C. K. Li AND N. S. SzE, Mappings on matrices: invariance of functional values of matrix products, J. Austral. Math. Soc., 81, 2, 2006, 165-184.

[8] J. T. CHAN, C. K. Li AND N. S. SzE, Mappings preserving spectra of products of matrices, Proc. Amer. Math. Soc., 135, 4, 2007, 977-986.

[9] J. Cui, V. Forstall, C.-K. Li And V. Yannello, Properties and preservers of the pseudospectrum, Linear Algebra Appl., 436, 2, 2012, 316-325.

[10] J. CUI AND C.-K. LI, Maps preserving peripheral spectrum of Jordan products of operators, Oper. Matrices, 6, 6, 2012, 129-146.

[11] J. Cui, C.K. Li AND Y.T. Poon, Pseudospectra of special operators and pseudospectrum preservers, J. Math. Anal. Appl., 419, 2, 2014, 1261-1273.

[12] J. CUi, C.K. Li And Y.T. PONn, Preservers of unitary similarity functions on Lie products of matrices, Linear Algebra Appl., 498, 1 June, 2016, 160-180.

[13] G. Dolinar, J. Hou, B. KuZma And X. QI, Spectrum nonincreasing maps on matrices, Linear Algebra Appl., 438, 8, 2013, 3504-3510.

[14] G. DobovišEK, B. KuZMa, G. LeŠnJAK, C.K. Li And T. PETEK, Mappings that preserve pairs of operators with zero triple Jordan product, Linear Algebra Appl., 426, 2-3, 2007, 255-279.

[15] H. GAO, *-Jordan-triple multiplicative surjective maps on B(H), J. Math. Anal. Appl., 401, 1, 2013, $397-403$

[16] J. HoU, K. HE AND X. ZHANG, Nonlinear maps preserving numerical radius of indefinite skew products of operators, Linear Algebra Appl., 430, 8-9, 2009, 2240-2253.

[17] J. C. HoU, C. K. LI AND N. C. WonG, Maps preserving the spectrum of generalized Jordan product of operators, Linear Algebra Appl., 432, 4, 2010, 1049-1069.

[18] L. Molnár, Some characterizations of the automorphisms of $B(H)$ and $C(H)$, Proc. Amer. Math. Soc., 130, 1, 2001, 111-120. 
[19] P. ŠEMRL, Non-linear commutativity preserving maps, Acta. Sci. Mah. (Szeged), 71, 3-4, 2005, 781819.

[20] L.N. Trefethen And M. Embree, Spectra and Pseudospectra, The Behavior of Nonormal Matrices and Operators, Princeton University Press, Princeton, 2005.

[21] W. Zhang AND J. Hou, Maps preserving peripheral spectrum of Jordan semi-triple products of operators, Linear Algebra Appl., 435, 6, 2011, 1326-1335. 